\title{
PROMOÇÃO DA ALFABETIZAÇÃO CIENTÍFICA (AC): CONSTRUÇÃO, FORMAÇÃO E DESENVOLVIMENTO NA PRÁTICA DOCENTE
}

\section{Promotion of Scientific Literacy (SL): Construction, Training and Development of Teacher Practices}

\author{
Werner Zacarias Lopes ${ }^{1}$ \\ Rosane Nunes Garcia ${ }^{2}$
}

\begin{abstract}
Resumo: O presente estudo teve como objetivo analisar as reflexões e entendimentos acerca da Alfabetização Científica que emergem posteriormente a um processo formativo de professores, bem como investigar as propostas didáticas elaboradas nos Planos de Aula (PA) com base nessa formação. Trata-se de uma pesquisa qualitativa que utiliza a pesquisa-ação como metodologia. Para a coleta de dados, foram aplicados questionários e, na sequência, foi ofertado um curso de formação continuada, enfocando a abordagem do tema AC para a prática docente nos Anos Iniciais do Ensino Fundamental. Também, realizaram-se observações in loco em torno das práticas docentes de três professores, que atuam em $4^{\circ}$ e $5^{\circ}$ anos de escolas públicas da rede municipal de Alegrete-RS. Entre os resultados obtidos, percebeu-se que a formação continuada serviu para que os professores reflexionassem sobre a sua própria prática, provocando mudanças no seu fazer docente. Na construção dos PA, os eixos estruturantes da AC foram incorporados aos objetivos propostos para as aulas. Por fim, nas observações in loco, notou-se o desenvolvimento e a promoção da AC na prática docente, especificamente na prática dos professores P4 e P6. A partir dos resultados obtidos nesta pesquisa, foi possível verificar como a formação continuada é necessária e importante para auxiliar na qualificação do Ensino das Ciências da Natureza nos Anos Iniciais do Ensino Fundamental.
\end{abstract}

Palavras-chave: Educação Científica. Formação de professores. Ensino de Ciências.

\begin{abstract}
This article aims to analyse the reflections and understandings about Scientific Literacy, which emerge after a process of teacher training. In addition, it intends to study the didactic proposals shown on the class plans based on this training. This qualitative research uses as methodology the Action-research. For data production, questionnaires were applied, $\mathrm{s}$ and then, a course of continued teacher training about Scientific Literacy for teacher practice

\footnotetext{
${ }^{1}$ Licenciado em Ciências Físicas e Biológicas pela Universidade da Região da Campanha- URCAMP, Mestrado em Educação em Ciências Química da Vida e Saúde, pela Universidade Federal de Santa Maria (UFSM) e doutorado pelo programa Educação em Ciências, Química da Vida e Saúde pela Universidade Federal do Rio Grande do Sul (UFRGS), professor da rede pública municipal de Alegrete/RS. Orcid: https://orcid.org/0000-0002-2951-1694. E-mail:wzl_al_pgq@yahoo.com.br.

${ }^{2}$ Licenciada em Ciências Biológicas (1992) e Bacharel em Ciências Biológicas (ênfase em genética) pela Universidade Federal do Rio Grande do Sul (1994); Mestre em Genética e Biologia Molecular (1997) e Doutora em Biologia Animal pela Universidade Federal do Rio Grande do Sul (2004), professora da carreira de EBTT no Colégio de Aplicação da Universidade Federal do Rio Grande do Sul. Orcid: https://orcid.org/0000-0002-4647-6245. E-mail: rosane.garcia@ufrgs.br.
} 
in the early years of Elementary School was offered . Furthermore, observations were carried out focused on the practices by three teachers who work with the fourth and fifth grades of public schools in the municipal system of Alegrete-RS. The results show that the continued training helped teachers to reflect about their own practices, making changes based on them. In the elaboration of class plans, the Scientific Literacy structural axes have been incorporated into the lesson objectives. Lastly, from observations, the development and promotion of Scientific Literacy on teacher practice were noticed, specially for P4 and P6 teachers.. It was possible to verify how the continued training is necessary and important to assist the Natural Science Teaching in the early years of Elementary School.

Keywords: Scientific Education. Continued Training. Science Teaching.

\section{Introdução}

Diversos estudiosos brasileiros da área do Ensino relacionado à pesquisa em Educação em Ciências (FRIZZO; MARIN, 1989; LORENZETTI, 2000; LORENZETTI; DELIZOICOV, 2001; FABRI; SILVEIRA; MONTEIRO, 2013; SOARES; MAUER; KORTMANN, 2013) têm se preocupado com o Ensino de Ciências (EC) na Educação Básica. Uma das problemáticas ressaltadas é referente às práticas educativas e à formação continuada de professores para o contexto dos Anos Iniciais do Ensino Fundamental. Interessados em contribuir para a qualidade do ensino desde os primeiros anos escolares, esses mesmos pesquisadores percebem que o desenvolvimento de práticas, voltadas para a formação continuada, proporciona aos professores o desenvolvimento de aprendizagens que permitem uma leitura de mundo com a linguagem da Ciência, visando um melhor entendimento das especificidades da educação científica e contribuindo para o desenvolvimento da Alfabetização Científica (AC).

No que se refere à formação de professores dos Anos Iniciais no EC, o desenvolvimento da AC é importante, pois, por meio de iniciativas didáticas e metodológicas, os docentes podem trabalhar com o conhecimento científico de forma mais apropriada com seus estudantes, mesmo durante o processo de apropriação do código escrito. O aprendizado das Ciências nos Anos Iniciais torna viável a interpretação e a compreensão de grande variedade de conhecimentos que permitem a percepção do mundo de forma mais integrada (BRASIL, 2017).

Para Maldaner (2003), a compreensão do papel das Ciências da Natureza na sociedade deve ser trabalhada por todos os educadores, a fim de proporcionar mudanças nas estruturas sociais vigentes. No entanto, para que isto ocorra, é importante que os professores estejam preparados para agir em favor dessas mudanças, sendo, para isso, indispensável a sua formação continuada. Diante desse imperativo elencado na literatura, Maldaner (2003) entende que o processo formativo é inerente à prática pedagógica, sempre mais difícil e de nível crescente de exigência de conhecimentos, da qual a formação inicial não pode dar conta.

Além disso, no entendimento de Nóvoa (1992), a formação do professor constrói-se através de tarefas de reflexividade, críticas sobre os métodos e de reconstrução constante do seu fazer pedagógico. Assim, entende-se que, a partir da importância de qualificar o EC e de desenvolver a AC, sejam necessárias ações formativas que aproximem o saber científico do saber tecnológico e do saber social, especialmente para os professores dos Anos Iniciais do Ensino Fundamental. 
Mas, para que seja possível verificar a efetividade de ações de formação continuada, é fundamental um olhar de acompanhamento, a fim de detectar as necessidades de mudanças no planejamento e nas ações dos formadores. Tendo em vista estas questões, a proposta desta pesquisa foi analisar aspectos relacionados ao EC nos Anos Iniciais, em especial, a respeito de trazer as reflexões e os entendimentos acerca da AC que emergem posteriormente a um processo formativo de professores, bem como investigar as propostas didáticas elaboradas com base nessa formação. Pesquisar esse contexto permite identificar se as concepções e os planejamentos dos professores apresentaram alguma mudança no contexto do ensino e da aprendizagem nas Ciências da Natureza nos Anos Iniciais.

\section{Alfabetização Científica e a formação continuada de professores}

A complexidade de fatores que permeiam a questão da formação continuada é ampla e está ligada ao desenvolvimento pedagógico da escola e da profissão docente. Para além da aprendizagem do conteúdo a ser ensinado em sala de aula, a formação de professores traz consigo aspectos relevantes que constituem o ser professor. Na formação para o EC, a AC se torna uma atividade essencial para desenvolvimento de uma educação científica capaz de promover a compreensão dos conhecimentos científicos em constante evolução.

Para Fumagalli (1998), o EC ainda vive uma contradição, pois, enquanto o discurso pedagógico é enfático na defesa do EC para a escolarização básica como um todo, o conhecimento científico e tecnológico é subestimado. Seu ensino ocupa um lugar superficial e, principalmente nos Anos Iniciais, chega a ser casual, o que não condiz com os documentos orientadores da educação brasileira, tais como os Parâmetros Curriculares Nacionais (2000) ou, mais recentemente, a Base Nacional Comum Curricular (2017). Esses documentos apontam para a importância da educação científica para Anos Iniciais e trazem diretrizes para o desenvolvimento das compreensões e interpretações sobre mundo e suas transformações.

Tão logo, a AC é um dos pressupostos do EC. Contudo, observa-se que o espaço escolar apresenta alguns desafios que dificultam a abordagem da AC. Dentre eles, podemos destacar métodos pedagógicos com a apresentação de conteúdos dogmáticos carentes de reflexões críticas, sem problematizações e contextualizações (CACHAPUZ et al., 2011), bem como a presença de lacunas na formação inicial e continuada dos professores (LOPES et al., 2017; OLDONI; LIMA, 2017).

O ensino das Ciências da Natureza, pautado pelo desenvolvimento da AC, tem um papel muito importante para que os alunos possam "fazer ciência", sendo defrontados com problemas autênticos nos quais a investigação seja condição para resolvê-los (SASSERON; CARVALHO, 2008). Para isso, como apontam as mesmas autoras, é importante que as aulas de Ciências tenham um entendimento público da Ciência em todos os aspectos e, também, que os alunos sejam levados à investigação científica, em busca da resolução de problemas e ao desenvolvimento de uma aprendizagem significativa.

Neste sentido, os professores dos Anos Iniciais necessitam de processos formativos que os ajudem a trabalhar o EC a partir da perspectiva da $\mathrm{AC}$ e de temáticas que sejam significativas para os alunos. Além disso, a utilização de métodos, como a problematização e contextualização com assuntos pertinentes e visando o interesse pelos conhecimentos científicos, são possibilidades plausíveis para seu desenvolvimento.

Diante disso, a AC para os Anos Iniciais constitui-se um desafio e a formação dos professores é um elemento essencial, já que os docentes têm poucas oportunidades de se aprofundar no conhecimento científico e na metodologia de EC, tanto quando sua formação 
ocorre em cursos de magistério, como em cursos de Pedagogia (BIZZO, 1998). Para Libâneo (2002), os professores dos Anos Iniciais precisam dominar conhecimentos e metodologias de campos específicos do conhecimento, tais como: Português, Matemática, História, Geografia, Ciências etc. Isso quer dizer que é preciso deixar de priorizar somente os conhecimentos da Matemática e da Língua Portuguesa, como tradicionalmente vem ocorrendo nos Anos Iniciais, e introduzir nas aulas conteúdos de outras áreas do conhecimento, como por exemplo as Ciências da Natureza (DELIZOICOV; SLONGO, 2011). Sendo assim, entende-se que a formação dos professores dos Anos Iniciais deve articular-se naturalmente ao trabalho docente, de modo a poder fornecer condições materiais, profissionais e intelectuais capazes de assegurar aos professores uma atuação educativa na perspectiva da AC (LORENZETTI; DELIZOICOV, 2001).

Corroborando com essa ideia, Sasseron e Carvalho (2008) identificam pontos principais a serem considerados no planejamento dos professores, quando se pensa em promover a AC, que tem sido chamado de "eixos estruturantes da Alfabetização Científica". Esses eixos possibilitam, além da aprendizagem das Ciências de forma significativa e contextualizada, a ampliação das compreensões das interações entre a Ciência, a Tecnologia e a Sociedade (CTS). Além disso, construir o planejamento pedagógico tendo por base os eixos estruturantes da AC, permite também a disseminação do conhecimento científico na sociedade (VIECHENESCKI; SILVEIRA, 2012).

Para Cachapuz et al. (2011), é preciso superar o ensino superficial, descontextualizado, empírico-indutivista, ateórico, aproblemático e ahistórico. Isso pode ser possível a partir de ações pedagógicas que mobilizem e propiciem a construção de conhecimentos, mediante a problematização e estudos de temáticas locais significativas. Porquanto, o professor, como agente que transforma e que faz parte da realidade do aluno, necessita buscar em sua formação continuada o suporte para ser o mediador no desenvolvimento de aprendizagens, criando espaços para a participação ativa do aluno, uma vez que propostas incorporadas nas dimensões da AC na abordagem da CTS têm como objetivo promover a contextualização da atividade científica na escola.

Com base nas ideias apresentadas, depreende-se que a formação continuada passa a ser uma possibilidade para sanar as lacunas deixadas pela formação inicial. Deste modo, favorecendo $o$ entendimento da importância da $\mathrm{AC}$ e as suas implicações nos desenvolvimentos de alunos críticos e reflexivos sobre assuntos de cunho científicos e relacionados às questões CTS, com isso, rompendo com práticas simplistas de ensino e de aprendizagem (CACHAPUZ et al., 2011).

\section{Metodologia}

Esta é uma pesquisa qualitativa de caráter exploratório (GIL, 2010) que buscou analisar, na primeira etapa, as reflexões dos professores geradas a partir do curso de formação continuada envolvendo as temáticas AC e CTS. Na segunda etapa, realizaram-se observações em sala de aula, a fim de analisar as aprendizagens dos professores, evidenciadas nos Planos Aulas (PA) construídos pelos docentes, utilizando os Eixos Estruturantes da AC de Sasseron e Carvalho (2011) como critérios de análise.

Quanto aos procedimentos técnicos utilizados, este estudo se caracteriza como pesquisa de campo (GIL, 2010). Este tipo de pesquisa é o recorte que o pesquisador faz em termos de espaço, representando uma realidade empírica a ser estudada a partir das concepções teóricas que fundamentam o objeto da investigação (MINAYO, 1992). As 
técnicas utilizadas para a coleta dos dados foram um questionário e a observação não participante (MINAYO, 1992). Usou-se a observação não participante para analisar a aplicação dos PA pelos professores e melhor compreender como as aprendizagens docentes ocorreram, desde a construção dos PA até o desenvolvimento em sua prática pedagógica.

Participaram, de maneira voluntária do presente estudo, três professores dos $4^{\circ}$ e $5^{\circ}$ anos do Ensino Fundamental. Atribuíram-se pseudônimos aos professores (P1, P3, P4) para resguardar a identificação dos mesmos e manter o anonimato. Os participantes da pesquisa assinaram um Termo de Consentimento Livre e Esclarecido.

Para contextualizar a participação destes professores, esclarece-se que essa participação só foi possível a partir do desenvolvimento, em uma etapa anterior, de um curso de formação continuada de vinte horas, organizado pelo pesquisador, no qual participaram 21 professores de $4^{\circ}$ e $5^{\circ}$ anos. Essa formação foi ofertada a professores pertencentes às escolas públicas da rede municipal de ensino de Alegrete, Rio Grande do Sul, que teve como objetivo trabalhar o Ensino de Ciências (EC) nos Anos Iniciais do Ensino Fundamental, considerando o desenvolvimento da AC e do ensino com enfoque CTS nas práticas pedagógicas.

Uma das proposições desta formação era ter um caráter teórico-prático, em que o pesquisador/formador atuou junto aos professores, em processos de reflexão teórica, assim como com a elaboração de propostas de aula que contemplassem a abordagem dos assuntos debatidos na formação. Assim, a intenção foi de colaborar com a construção de práticas que fomentem o desenvolvimento da $\mathrm{AC}$ dos estudantes para questões atinentes, por exemplo, à ciência e à tecnologia e suas interações. A reflexão teórica partiu de problemática sobre EC trazida pelos professores e envolveu a participação ativa de todos em atividades de leitura e debates a respeito de textos acadêmicos sobre AC e CTS, e a sistematização dos conhecimentos através da construção de cartazes e mapas conceituais, construção de planejamentos de forma colaborativa entre pesquisador e professores, considerando as reflexões teóricas desenvolvida pelo grupo.

Como materiais resultantes da formação, para posterior análise, foram obtidos vinte e um PA, elaborados pelos professores. Todos os participantes da formação foram convidados a aplicarem os PA em suas turmas. Do convite feito, apenas quatro professores (P1, P4, P6 e P10) aceitaram que suas práticas fossem observadas. Neste trabalho, excluíram-se os dados referentes ao PA do P10, em virtude de que o PA, elaborado por este professor, não contemplava o contexto de aplicação dos objetivos propostos na formação, que foi para os $4^{\circ}$ e $5^{\circ}$ anos do ensino fundamental. Mesmo assim, considerou-se a opinião do P10 ao analisar as suas respostas dadas ao questionário aplicado. O período do desenvolvimento da formação continuada de professores foi o segundo semestre do ano de 2018, compreendendo as ações tanto da observação quanto da aplicação do questionário para a coleta de informações desta pesquisa.

O método de análise usado para os documentos foi a do tipo análise de conteúdo, tendo como suporte Bardin (2011), a qual apresenta esse método como um conjunto de técnicas de análise das comunicações, que utiliza procedimentos sistemáticos e objetivos de descrição do conteúdo das mensagens. Utilizou-se o critério semântico para a categorização na análise da $1^{\circ}$ etapa dos planejamentos. Com base nisso, foram construídas categorias de análise a priori, as quais estão organizadas em duas seções. A primeira delas, intitulada de "Formação continuada de professores: reflexões importantes para a prática pedagógica", e a segunda seção, intitulada de "Aprendizagens dos professores sobre a compreensão de conceitos básicos, da natureza das ciências e das interações CTS(A)". 
Esta pesquisa foi aprovada pelo Comitê de Ética em Pesquisa (CEP) da Universidade Federal do Rio Grande do Sul, conforme os termos da Resolução no . 466/2012 e 510/2016 do Conselho Nacional de Saúde (Parecer nº 2.659.539, de 17 de maio de 2018).

\section{Resultados e Discussão}

A análise e discussão dos dados obtidos estão organizados em duas seções. A primeira delas, intitulada de "Formação continuada de professores: reflexões importantes para a prática pedagógica", apresenta a visão dos professores sobre o desenvolvimento do curso de formação continuada envolvendo as temáticas AC e CTS, onde os docentes responderam um questionário. Na segunda seção, intitulada de "Aprendizagens dos professores sobre a compreensão de conceitos relacionados a CTS(A)", evidencia as possíveis aprendizagens dos professores que participaram da formação continuada, e envolvem questões essenciais no desenvolvimento do Ensino de Ciências (EC), que são tratadas a partir dos eixos estruturantes da AC. A análise destas aprendizagens foi realizada a partir dos Planos de Aula elaborados pelos professores durante a formação e da aplicação destes planejamentos em sala de aula, que foram observados pelo pesquisador in loco.

\subsection{Formação continuada de professores: reflexões importantes para a prática pedagógica}

Em outro momento que antecede esta pesquisa, os mesmos professores, que participaram do curso de formação continuada, responderam um questionário que pretendia conhecer as suas concepções sobre conceitos entre Ciência, Tecnologia, Sociedade (CTS) e suas interações. Dos resultados obtidos neste questionário, observou-se que os professores apresentaram uma falta de informação ou de não clareza sobre as inter-relações entre CTS. Essas compreensões podem influenciar, produzindo uma visão fragmentada dos conceitos de Ciência e de Tecnologia e suas interações nas práticas escolares. A análise dessas concepções foi importante para perceber que, para quem trabalha com o ensino das Ciências da Natureza, as compreensões acerca desses temas trazem implicações nas práticas pedagógicas e podem ter reflexo na aprendizagem dos estudantes.

A partir desses resultados anteriores, a formação continuada ofertada teve como objetivo incentivar os professores dos Anos Iniciais a pensar em um EC que possa desenvolver a AC juntos aos estudantes desde os primeiros anos da escolarização formal. Sensibilizar o professor para a importância do desenvolvimento da AC nos Anos Iniciais é relevante, pois, é possível introduzir conhecimentos científicos para os estudantes em práticas relativas ao EC que resultam em vários benefícios ${ }^{3}$ (LORENZETTI, 2000; VIECHENESKI; CARLETTO, 2013). Em vista disso, acredita-se na importância da formação continuada como uma estratégia que pode oferecer subsídios fundamentais para reflexão da própria prática pedagógica do professor, e este desenvolver estratégias necessárias para colaborar com a qualidade do EC nos Anos Iniciais.

Com base nos dados da presente pesquisa, coletados ao final da formação continuada, emergiram duas categorias de análise a partir das respostas dadas pelos professores, as quais

\footnotetext{
${ }^{3}$ A exemplo, tem-se a ampliação dos conhecimentos dos estudantes sobre as ciências, o despertar da curiosidade, o desenvolvimento do senso de observação e o interesse pelos temas científicos (LORENZETTI, 2000; VIECHENESKI; CARLETTO, 2013).
} 


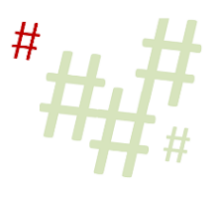

são apresentadas e discutidas na sequência. A primeira categoria traz um olhar dos professores sobre o processo de formação continuada, e a segunda categoria trata sobre as mudanças percebidas pelos professores em sua prática pedagógica decorrente do desenvolvimento da formação continuada.

\subsubsection{A visão dos professores sobre a formação continuada}

Entre as análises dos relatos, destaca-se que o professor P1 traça um paralelo de sua trajetória profissional, desde a sua formação inicial, destacando uma busca constante de melhorar sua prática.

Para o professor $\mathrm{P} 4$ a formação levou a refletir sobre sua própria prática pedagógica. $\mathrm{O}$ professor relata sobre a importância de momentos como a formação continuada, que possibilitam mudanças, em especial, as que estão relacionadas aos seus desejos e opções e que podem começar com a reformulação de suas próprias práticas, no intuito de revitalizar a sua postura enquanto educador. $\mathrm{O}$ anseio do professor P4 é que os novos saberes possam ser democráticos, beneficiando a si e ao seu próximo, tornando o mundo mais sociável, forte e afetuoso nas relações, partindo da educação ao alcance de todos, sem distinção. Anseio este que ele observa em mudanças de sua prática enquanto docente a partir desta formação continuada.

O professor P6 relata que todo o processo de formação continuada sempre provoca uma mudança, seja na prática pedagógica ou na maneira de pensar a educação. O professor P6 menciona que, com algum tempo na docência, muitas vezes a tendência é de se acomodar com práticas costumeiras, menos ousadas, e ao participar de encontros de formação como este, recebeu um novo estímulo fazendo com que acredite que é possível fazer a diferença na prática da sala de aula. Para P6 a formação provocou desacomodação ao propor a utilização de conhecimentos em torno do EC com enfoque CTS integrado com os conteúdos do $4^{\circ}$ ano, bem como na percepção das necessidades do processo de formação continuada para melhorias na educação. Entre as mudanças citadas pelo professor está a dos conhecimentos sobre a abordagem da CTS e as possibilidades de sua aplicação na prática pedagógica. Para o professor P10, trata-se da aquisição de novos conhecimentos a partir da troca de ideias entre os professores dos $4^{\circ}$ e $5^{\circ}$ anos (experiências).

De modo geral, os professores ressaltam que o processo de formação trouxe contribuições no jeito de pensar, planejar e agir nas práticas pedagógicas no ensino das Ciências. A formação foi entendida pelos professores como parte do processo de desenvolvimento de novos saberes, que acontece também na sua vida escolar que, para Nóvoa (1992), é um processo longo, sem um fim determinado para novas aprendizagens.

\subsubsection{Implicações evidenciadas nas práticas docentes}

Uma das possibilidades que o professor P1 percebeu, em relação à atividade de formação e estudos oferecidos, foi a de poder reflexionar sobre a própria prática docente, fazendo com que buscasse mais experiência para ensinar aos seus estudantes sobre as questões relacionadas à vida, à natureza e ao homem. O professor $\mathrm{P} 1$ reconhece a importância sobre todo o processo da $\mathrm{AC}$, o que torna mais acessível a aprendizagem dos estudantes, pois, eles visualizam e criam os seus próprios conceitos científicos. Na visão de P1, embora seja mais cansativo trabalhar aulas práticas com experimentação antes de aulas expositivas, por exemplo, possibilita desenvolver aprendizagens relacionadas à vida do homem e da natureza. 
O professor P4, após participar da formação, sentiu a necessidade de mudança no planejamento das suas aulas, considerando os interesses de cada aluno. A formação oportunizou ao docente uma busca de novos caminhos na prática pedagógica como as leituras, os debates, as experiências e as trocas no grupo. Segundo P4, estas vieram a somar com novas metodologias e projetos que o docente pretende atingir com a turma, no intuito de despertar em cada aluno o interesse e o prazer da descoberta. Isso, para que eles formulem ideias, hipóteses e desenvolvam o senso crítico, construindo o seu conhecimento.

O professor P6 relata sobre algumas dessas mudanças na sua prática docente. Segundo ele, a formação contribuiu com acréscimos no sentido de qualificar o trabalho interdisciplinar, além de favorecer a realização de aulas mais criativas e dinâmicas com a utilização de experimentos, que colaboram com o desenvolvimento das aprendizagens significativas aos alunos. Para o professor P10 as mudanças proporcionadas pela formação, em relação ao seu fazer docente, serviram para despertar o interesse e o prazer dos estudantes durante a realização das atividades voltadas para EC.

A partir das respostas dos professores, pode-se notar possíveis mudanças no modo de pensar e de planejar as aulas de Ciências nos $4^{\circ}$ e $5^{\circ}$ anos. Pela observação realizada em sala de aula e pela análise dos PA dos professores, verificou-se que a maioria dos docentes trabalharam de forma interdisciplinar e contextualizada, possibilitando, com isto, aulas mais criativas e dinâmicas. Também, foram identificadas a utilização de metodologias diferenciadas, como o uso da observação, da experimentação e de trabalhos lúdicos. Essas questões observadas levam a crer que a formação continuada contribuiu para o desenvolvimento de novos saberes e de novas aprendizagens, trazendo novas possibilidades de trabalhar e (re)significar a prática pedagógica docente.

O relato dos professores evidencia reflexões de mudança na própria prática pedagógica, com isso, suscitando que é possível acreditar na valorização e no incentivo dos processos de formação continuada de professores dos Anos Iniciais, como uma alternativa para apoiar a melhoria do EC. Hargreaves (2002, p. 114) colabora nessa discussão ao destacar que "os professores precisam de chances para experimentar a observação, a modelagem, a instrução individual, a prática, feedback", a fim de que tenham a possibilidade de desenvolver novas habilidades e de torná-las uma parte integrante de suas rotinas de sala de aula. A formação, assim entendida, permitiu, aos professores, a reconstrução e a reflexão de suas práticas pedagógicas, a fim de tornar possível o desenvolvimento da criticidade e a compreensão de novos saberes (MAZZEU, 1998), a partir da perspectiva da AC.

\section{2 Aprendizagens dos professores sobre a compreensão de conceitos relacionados a CTS(A)}

Este estudo considerou a análise dos PA dos professores e da sua aplicação nas aulas como um dos elementos fundamentais para avaliar as aprendizagens produzidas pela formação. Os eixos estruturantes da AC, utilizados por Sasseron e Carvalho (2011), foram empregados como parâmetros para identificar e avaliar, nos PA e na sua aplicação, como os professores desenvolviam cada eixo em sua prática docente. O Quadro 1 apresenta os eixos estruturantes da AC identificados nos PA e durante a aplicação destes planejamentos por parte dos docentes. 
Quadro 1 - Análise dos indicadores do desenvolvimento da AC nos planos de aulas e na execução do planejamento por parte dos professores de $4^{\circ}$ e $5^{\circ}$ anos, tendo como base os Eixos Estruturantes da AC.

\begin{tabular}{|c|c|c|c|}
\hline $\begin{array}{c}\text { EIXOS } \\
\text { ESTRUTURANTES } \\
\text { DAAC** } \\
\end{array}$ & $\begin{array}{c}\text { PLANOS DE AULA DO } \\
\text { PROFESSOR }\end{array}$ & APLICAÇÃO DOS PLANOS DE AULA & PROFESSOR \\
\hline \multirow{3}{*}{$\begin{array}{l}\text { Compreensão } \\
\text { básica de termos, } \\
\text { conhecimentos e } \\
\text { conceitos } \\
\text { científicos } \\
\text { fundamentais. }\end{array}$} & Não foi identificado. & $\begin{array}{l}\text { Desenvolveu conceitos gerais sobre a } \\
\text { densidade dos objetos, comentou sobre as } \\
\text { relações entre peso, massa e volume. }\end{array}$ & $\mathrm{P} 1$ \\
\hline & Não foi identificado. & $\begin{array}{l}\text { Desenvolveu conceitos gerais e } \text { a } \\
\text { compreensão do processo digestório, a } \\
\text { função das enzimas e a constituição dos } \\
\text { alimentos pelo amido. }\end{array}$ & P4 \\
\hline & $\begin{array}{lr}\text { Foram } & \text { identificados } \\
\text { objetivos } & \text { como } \\
\text { caracterizar, } & \text { observar, } \\
\text { estabelecer e compreender. }\end{array}$ & $\begin{array}{l}\text { Desenvolveu termos e conceitos gerais } \\
\text { sobre os anelídeos, minhocário, nutrição } \\
\text { vegetal e a partir destes partiu para o } \\
\text { conhecimento científico específico dos } \\
\text { anelídeos.' }\end{array}$ & P6 \\
\hline \multirow{3}{*}{$\begin{array}{lr}\text { Compreensão } & \text { da } \\
\text { natureza } & \text { das } \\
\text { ciências e } & \text { dos } \\
\text { fatores éticos } & \text { e } \\
\text { políticos } & \text { que } \\
\text { circundam } & \text { sua } \\
\text { prática. } & \\
\end{array}$} & $\begin{array}{l}\text { Uso de experimentação: } \\
\text { planejamento de uma aula } \\
\text { demonstrativa sobre } \\
\text { densidade dos objetos. }\end{array}$ & $\begin{array}{l}\text { Foi observado parcialmente, pois a } \\
\text { professora demonstrou quais objetos eram } \\
\text { mais ou menos densos entre sólidos e } \\
\text { líquidos e entre líquidos e líquidos. Os } \\
\text { estudantes apenas observaram a } \\
\text { demonstração. }\end{array}$ & P1 \\
\hline & $\begin{array}{l}\text { Uso da experimentação. } \\
\text { Planejamento de uma aula } \\
\text { prática. Observar se os } \\
\text { alimentos são constituídos } \\
\text { por amido, utilizando } \\
\text { tintura de iodo. }\end{array}$ & $\begin{array}{l}\text { A realização de experimentação por parte } \\
\text { dos estudantes e com a orientação da } \\
\text { professora para identificar a presença do } \\
\text { amido. }\end{array}$ & P4 \\
\hline & $\begin{array}{l}\text { Uso da experimentação. } \\
\text { Planejamento de uma aula } \\
\text { prática para construção de } \\
\text { um minhocário. }\end{array}$ & $\begin{array}{l}\text { Culminância do plano de aula foi a } \\
\text { construção do minhocário. Com a } \\
\text { participação dos estudantes, sob orientação } \\
\text { da professora. }\end{array}$ & P6 \\
\hline \multirow{3}{*}{$\begin{array}{l}\square \text { Entendimento das } \\
\text { relações existentes } \\
\text { entre CTSA. }\end{array}$} & Não foram identificados. & Não foram observados & $\mathrm{P} 1$ \\
\hline & Não foi identificado. & $\begin{array}{l}\text { Ao trabalhar alimentação saudável, a } \\
\text { professora conseguiu relacionar aspectos da } \\
\text { Ciência com a Sociedade. }\end{array}$ & $\mathrm{P} 4$ \\
\hline & $\begin{array}{l}\text { Foram identificadas nos } \\
\text { objetivos específicos as } \\
\text { relações de conservação e } \\
\text { melhoria do meio } \\
\text { ambiente. }\end{array}$ & $\begin{array}{l}\text { Entrelaçou nas atividades de sala de aula a } \\
\text { relação do uso dos agrotóxicos na } \\
\text { agricultura e os problemas causados ao } \\
\text { meio ambiente e às pessoas. }\end{array}$ & P6 \\
\hline
\end{tabular}

Legenda: *Indicadores da Alfabetização Científica, elencados por Sasseron e Carvalho (2011). Fonte: Os autores (2018).

Conforme exposto no Quadro 1, o PA do professor P1 está diferente do modelo de plano entregue na formação continuada, onde não estão explícitos os objetivos e os procedimentos que foram utilizados na atividade planejada. No PA, apenas continha a descrição dos materiais para a realização do experimento e a explicação do conteúdo sobre a densidade. Também não foram identificados objetivos relacionados ao primeiro eixo estruturante que levassem à compreensão básica de termos científicos. Isto talvez indique a necessidade de mais estudos, não só sobre os referenciais teóricos que tratam da perspectiva 


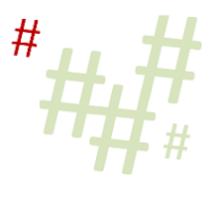

da $\mathrm{AC}$, como também daqueles que tratam da importância do planejamento e didática das ciências.

Ao colocar em prática o PA, o professor P1 demonstrou de forma expositiva em sua aula atitudes iniciais no desenvolvimento de conceitos gerais e específicos sobre densidade dos objetos, relações entre peso, massa e volume. A ausência de objetivos e dos procedimentos adotados foi percebida no decorrer do desenvolvimento da prática de sala de aula. Isso talvez seja uma forma inicial de trabalhar a AC com os alunos, pois possibilita entender a construção inicial de conceitos-chave e até mesmo pequenas informações e situações do dia a dia (CACHAPUZ et al., 2011).

Observou-se que, no PA do professor P1, o planejamento de uma aula experimental pode ser configurado como uma possível aplicação do eixo estruturante relacionado à compreensão da natureza das ciências. Entretanto, durante a observação em sala de aula, pode-se perceber que apenas o professor manipula os objetos para demonstrar quais afundam ou flutuam na água. Com isso, constatou-se que a participação parcial dos alunos durante o processo, que agem de forma mais ativa na aula apenas a partir de um jogo entre equipes, os quais ficam eufóricos e participativos na brincadeira, respondendo quais objetos afundam ou flutuam. Embora não haja a manipulação na experimentação por parte dos alunos, alguns conceitos gerais e específicos sobre densidade, volume, peso e massa são trabalhados de forma lúdica. É importante, porém, considerar o que Cachapuz et al. (2011) destacam, pois os autores consideram que não basta apenas teorizar e trabalhar a prática experimental, tem que problematizar e contextualizar para que se tenha uma aproximação significativa com o conhecimento científico e que tenha sentido para a vida dos estudantes.

Não foram identificados aspectos relativos ao último eixo estruturante (relações entre CTS(A)) nos PA e na observação da aula prática do professor P1. Ele basicamente estrutura seus procedimentos a partir de aulas expositivas e de experimentação. Isso, talvez seja reflexo de uma não compreensão da importância de trabalhar os conhecimentos científicos atrelados às questões que dizem respeito a ciência e a tecnologia e o que ambas refletem em aspectos positivos e negativos na sociedade. Esta aproximação tenderia a promover uma ampla relação entre a ciência, a tecnologia, a sociedade e o ambiente a partir de atividades dirigidas para a compreensão destas (FREIRE, 2007).

Ao analisar o PA do professor P4 verificamos que está estruturado de forma simples, com o início e o fim do planejamento, levando a crer que o professor tem uma preocupação em estabelecer quais são seus objetivos e de como, e de que forma, será realizada sua aula. Não foram identificados, dentro dos objetivos e procedimentos, aspectos relacionados à compreensão básica de termos e conceitos científicos, um dos eixos necessários para o desenvolvimento da AC.

Embora o professor não tenha explicitado no PA os objetivos ligados aos conceitos científicos, observa-se que, na aplicação do PA, o professor consegue desenvolver conteúdos conceituais sobre o processo digestório, a função das enzimas e a constituição dos alimentos por amido, gorduras e sais minerais. É importante ressaltar que o professor começou a temática perguntando aos alunos sobre como é a alimentação em casa e na escola, isto demonstra a preocupação do professor em contextualizar e dar sentido aos conteúdos a partir das vivências e das práticas de vida dos estudantes sobre a alimentação.

O professor P4 utilizou esquemas do sistema digestório na forma de desenho em uma folha, onde os estudantes preencheram cada órgão com massa de modelar em diferentes cores, contendo legendas com as funções de cada órgão humano (Figura 1). Partindo da observação em sala de aula, identificou-se que os conceitos e a compreensão básica do conhecimento 
científico estão de acordo com o processo inicial da AC, servindo de subsídio para construção dos primeiros significados e, com isso, levando à compreensão de conceitos-chave para interpretar informações que serão entrelaçadas com o cotidiano dos alunos. (LORENZETTI; DELIZOICOV, 2001; SASSERON; MACHADO, 2017).

Figura 1 - Esquema do sistema digestório realizado com massa de modelar pelos alunos durante a prática do professor $\mathrm{P} 4$

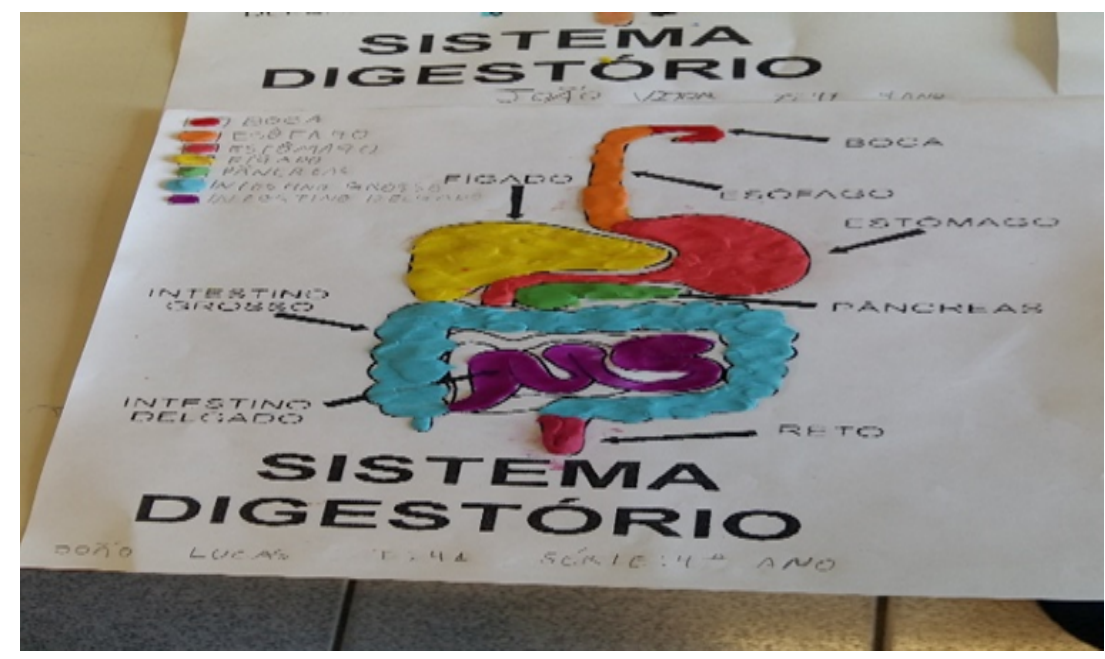

Fonte: Os autores (2018).

No PA do professor P4 consta também uma aula experimental para explicar a existência de amido em alguns alimentos ingeridos pelos alunos, utilizando uma solução de tintura de iodo. Durante a atividade, observou-se que o professor P4 orientou seus alunos fazendo-os manipular, observar e anotar as possíveis mudanças ocorridas com os alimentos, a partir do uso da solução (Figura 2).

Figura 2 - Aula experimental realizada com os estudantes sobre a ingestão de alimentos durante a prática do professor P4

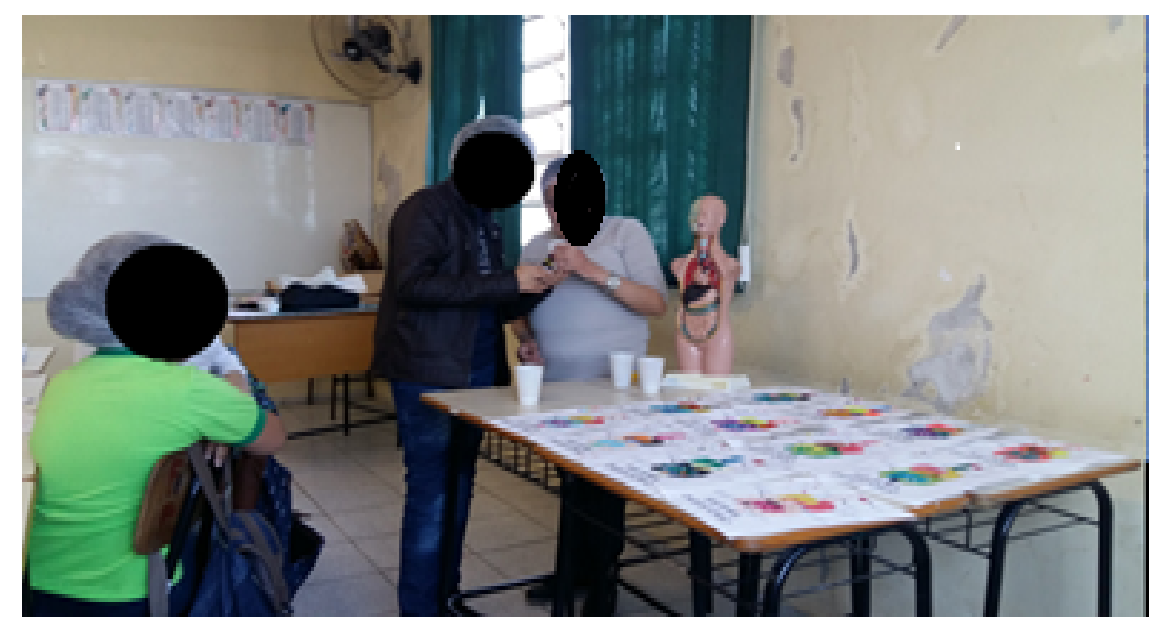

Fonte: Os autores (2018). 
Ao orientar os estudantes durante a aula prática, o professor participa como mediador do processo, estimulando a curiosidade, a autonomia, o desenvolvimento da atenção e da observação. Desta forma, há um avanço para além dos conteúdos conceituais, realizando procedimentos e observações que, de acordo com Santos (2007), levam à leitura e à compreensão de significados, vocábulos e interpretação de resultados e contemplando, assim, aspectos relacionados ao eixo estruturante da compreensão da natureza das ciências.

Observa-se que, ao final da aula, esse professor confecciona com seus alunos barras de cereais para estimular o hábito de ingerir alimentos saudáveis. Nesta etapa, percebe-se que as relações entre CTS estão inseridas no trabalho realizado pelo professor, ao reflexionar com os alunos a respeito de atitudes recomendáveis e sobre os riscos à saúde resultantes de uma má alimentação. Santos e Mortimer (2002) destacam que abordagens como a alimentação saudável trabalhadas pelo professor em aula possibilitam o entendimento dos alunos a respeito dos impactos causados pela ciência e pela tecnologia em uma sociedade que se alimenta mal e as consequências de ter muitas pessoas obesas e com problemas cardíacos em decorrência dos maus hábitos alimentares. Por fim, destaca-se que o trabalho desenvolvido pelo professor P4 contemplou os três eixos estruturantes da AC, já que o mesmo parte dos conceitos, passa pela natureza das ciências e finaliza entrelaçando a CTS com o cotidiano dos estudantes.

A análise do PA do P6 demonstra que o planejamento contempla os três eixos estruturantes da AC, a partir dos objetivos indicados no documento. Em acordo com o primeiro eixo, foram identificados objetivos de trabalhos relacionados às características, observações e à compreensão dos conceitos e termos científicos básicos relacionados à composição e tipos de solo e anelídeos. Com relação ao segundo eixo, o professor planejou a construção de um minhocário como parte de uma aula prática. O último eixo é contemplado com os objetivos específicos relacionados à conservação do solo e da água e os problemas causados pelo uso excessivo de agrotóxicos.

O PA do professor P6 estrutura-se metodologicamente de forma coerente com o propósito de promover a $\mathrm{AC}$, o que demonstra que o docente tem familiaridade com o planejar e com o estudar. Lorenzetti e Delizoicov (2001) afirmam que a organização e o planejamento podem garantir abordagens de conteúdos científicos estruturados a partir de conceitos, procedimentos e atitudes que se relacionam com as ideias explicitadas sobre o desenvolvimento da AC.

Ao observar na sala de aula a execução do PA, verifica-se que o professor P6 estabeleceu contextualizações dos conteúdos a partir da realidade dos alunos, buscando desenvolver a compreensão de termos e conceitos ao utilizar características, observações sobre solo, água, nutrição vegetal, húmus e minhocas (anelídeos). Além disso, o professor introduziu, durante este processo, conceitos específicos relativos às minhocas e às partes do corpo dos anelídeos em um trabalho interdisciplinar com componente curricular de Artes, a partir da construção de minhocas com material alternativo, utilizando meias velhas e EVA (Figura 3). Outras importantes atividades, observadas na aula do professor P6, foram as retomadas de conceitos anteriormente trabalhados e o levantamento de questionamentos para elaboração de novos conhecimentos a partir de produção textual dos alunos. 
Figura 3 - Trabalho do professor P6 com os estudantes sobre anelídeos

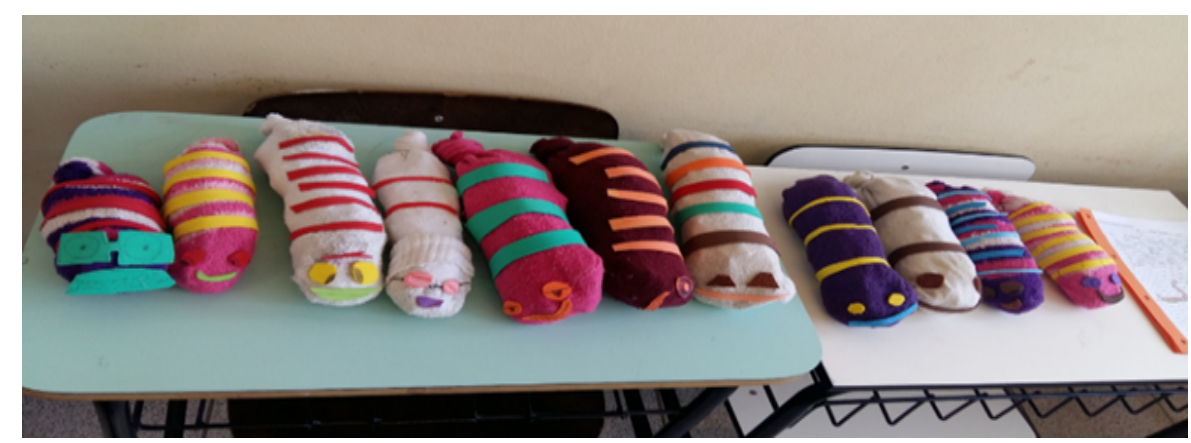

Fonte: Os autores (2018).

$\mathrm{Na}$ análise do PA e na observação da aula do professor P6, verifica-se que aspectos relacionados à construção da AC estão inseridos no planejamento e nas atividades desenvolvidas em aula. Esses aspectos vêm promover o desenvolvimento da articulação dos conceitos científicos com objetivos e finalidades para o EC, utilizando-se de propostas que se aproximem de questões e que ampliem a capacidade de ler, escrever e interagir com uma nova linguagem científica de mundo (NORRIS; PHILLIPS, 2003; CHASSOT, 2006; SASSERON; CARVALHO, 2011).

O professor P6 estimula seus alunos a construir minhocário com garrafas pets, a partir de cascas de frutas e de verduras, terra e minhocas californianas (utilizadas em minhocário), para a produção de húmus. $\mathrm{Na}$ finalização da construção do minhocário pelos alunos, observa-se que o professor estimula questionamentos e retoma conceitos básicos e específicos, mediando a reconstrução do conhecimento científico. Para Petrucci e Ure (2001), um dos objetivos das aulas práticas de experimentação é o da observação, que levaria a uma educação científica e garantiria aos alunos meios para adquirir, de certo modo, uma compreensão adequada da natureza da ciência. Na finalização da aula, o professor P6 entrelaça os conhecimentos científicos adquiridos utilizando um vídeo sobre agricultura familiar, agrotóxicos e os prejuízos à saúde e ao meio ambiente.

Nesse fechamento, observa-se que, de certo modo, o professor busca criar nos alunos a capacidade de relacionar conceitos científicos de diferentes áreas do conhecimento, estimulando seu pensamento crítico, promovendo o debate do grupo acerca da liberação e utilização dos agrotóxicos e os prejuízos que estes causam na saúde e no ambiente. Esta articulação dos saberes com a inclusão de temas sociais como este, na construção de conceitos científicos, promove mudanças conceituais e contribui para a AC, que está imbricada com as relações CTS. Apoia-se em Lorenzetti e Delizoicov (2001) quando esses autores destacam sobre um amplo leque de atividades que, articuladas com planejamento escolar, possibilitam a AC e o enfoque CTS. Dentro de muitas atividades, os autores indicam a utilização de vídeos educativos que contribuem significativamente para um trabalho na perspectiva da AC.

De modo geral, pode-se verificar que nas três observações realizadas in loco, um professor (P1) não desenvolveu por completo os três eixos estruturantes, planejando e aplicando apenas aulas expositivas e desenvolvendo tão-somente conceitos gerais. Para os professores P4 e P6, verifica-se que estes docentes planejaram e desenvolveram atividades capazes de envolver os estudantes em situações que possibilitam tornarem-se alfabetizados cientificamente. 


\section{Conclusão}

Este artigo teve a finalidade de contribuir com reflexões sobre o EC nos Anos Iniciais do Ensino Fundamental, bem como sobre a formação de professores de $4^{\circ}$ e $5^{\circ}$ anos. Entrelaça considerações sobre as razões de ensinar Ciências nos anos $4^{\circ}$ e $5^{\circ}$ anos, particularmente pela necessidade de uma AC capaz de propiciar uma compreensão mais adequada do que é disseminado nos cursos de formação inicial, sobretudo em relação a temas atuais referentes a CTS.

Com os resultados deste estudo, pode-se verificar que, na primeira etapa, que trata sobre a visão dos professores sobre o desenvolvimento do curso de formação continuada envolvendo as temáticas da $\mathrm{AC}$ e $\mathrm{CT}$, eles ressaltaram que o processo trouxe contribuições no jeito de pensar, planejar e agir nas práticas pedagógicas no EC. Além disso, acredita-se que um novo sentido à prática de sala de aula foi estabelecido, pois, na busca por conhecimento, os professores participantes debruçaram-se na procura por um melhor entendimento sobre a importância do EC e a perspectivas da AC e CTS nos seus planejamentos escolares. Nos relatos dos professores, evidenciam-se reflexões a respeito de mudanças nas práticas pedagógicas e, com isso, indica que é possível acreditar na valorização e nos incentivos dos processos de formação continuada dos professores dos $4^{\circ}$ e $5^{\circ}$ anos como alternativa para melhorar e qualificar o EC.

Em relação às análises do $\mathrm{PA}$, pode-se perceber que os professores tiveram intenções e interesse em desenvolver seus planejamentos em acordo com as orientações propostas na formação. Nas observações em sala de aula dos professores participantes da pesquisa, verificou-se que dois professores desenvolveram seus PA conforme planejado previamente durante a formação. Nessas duas observações, pode-se constatar que os PA e a aplicação destes em sala de aula estavam em conformidade com os três eixos estruturantes para o desenvolvimento da AC.

De modo geral, a formação proporcionou uma reflexão sobre a prática pedagógica do EC na perspectiva da AC e também na maneira de pensar e planejar as aulas de ciências, levando em conta que o EC também estimula o ensino e a aprendizagem dos estudantes em outras áreas do conhecimento.

\section{Referências}

BARDIN, L. Análise de Conteúdo. Lisboa: Edições 70, 2011.

BIZZO, N. Ciências: fácil ou difícil? São Paulo: Ática, 1998.

BRASIL. Ministério da Educação/Secretaria de Educação Básica. Base Nacional Curricular Comum. Brasília: MEC, 2017.

BRASIL. Secretaria de Educação Fundamental. Parâmetros Curriculares Nacionais: Ciências Naturais. Rio de Janeiro: DP\&A, 2000.

CACHAPUZ, A.; GIL PÉREZ, D.; CARVALHO, A. M. P; PRAIA, J.; VILCHES, A. Superação das visões deformadas da ciência e da tecnologia: um requisito essencial para a renovação da educação científica. In: CACHAPUZ et al. (org.). A necessária renovação do ensino das ciências. (p. 37-70). São Paulo: Cortez, 2011. 
CHASSOT, A. Alfabetização Científica: questões e desafios para a educação. $4^{\mathrm{a}}$ ed. Ijuí: Ed. Unijuí, 2006.

DELIZOICOV, N. C; SLONGO, I. I. P. O ensino de Ciências nos anos iniciais do Ensino Fundamental: elementos para uma reflexão sobre a prática pedagógica. Série-Estudos Periódico do Programa de Pós-Graduação em Educação da UCDB, n. 32, p. 205-221, jul./dez. 2011.

FABRI, F.; SILVEIRA, R.; MONTEIRO, C. F. O ensino de ciências nos anos iniciais do ensino fundamental sob a ótica CTS: uma proposta de trabalho diante dos artefatos tecnológicos que norteiam o cotidiano dos alunos. Investigações em Ensino de Ciências, v. 18, n. 1, p. 77-105, 2013.

FREIRE, L. I. F. Pensamento crítico, enfoque educacional CTS e o ensino de química. Tese. (Doutorado em Educação Científica e Tecnológica) - Universidade Federal de Santa Catarina, Programa de Pós-Graduação em Educação Científica e Tecnológica. Florianópolis: UFSC, 2007. $175 \mathrm{f}$.

FRIZZO, M. N.; MARIN, E. B. O ensino de ciências nas Séries Iniciais. Ijuí: UNIJUÍ, 1989.

FUMAGALLI, L. O ensino de Ciências naturais no nível fundamental de educação formal: argumentos a seu favor. In: WEISSMANN, Hilda (org.). Didática das Ciências Naturais: contribuições e reflexões. Porto Alegre: ArtMed, 1998.

GIL, A. C. Métodos e técnicas de pesquisa social. 6.ed. São Paulo: Atlas, 2008.

HARGREAVES, A. Aprendendo a mudar: o ensino para além dos conteúdos e da padronização. Porto Alegre: Artmed, 2002.

LIBÂNEO, J. C. Ainda as perguntas: o que é pedagogia, quem é o pedagogo, o que deve ser o curso de Pedagogia. In: PIMENTA, Selma Garrido (org.). Pedagogia e pedagogos: caminhos e perspectivas. São Paulo: Cortez, 2002.

LOPES, W. Z. L.; JESUS, R. F.; FOMER, V.; PUNTEL, R. L. Concepções de professoras dos anos iniciais sobre a Alfabetização Científica (AC) e a abordagem Ciência, Tecnologia e Sociedade (CTS) no Ensino de Ciências. Revista Ciências e Ideias, v. 8, n. 1, p. 01-22, jan, 2017.

LORENZETTI, L. Alfabetização Científica no contexto das séries iniciais. Dissertação (Mestrado em Educação) - Centro de Ciências da Saúde, Universidade Federal de Santa Catarina. Florianópolis: UFSC, 2000. 143f.

LORENZETTI, L.; DELIZOICOV, D. Alfabetização científica no contexto das séries iniciais. Ensaio - Pesquisa em Educação em Ciências, v. 3, n. 1, jun, 2001.

MALDANER, O. A. A Formação Inicial e Continuada de Professores de Química Professor/Pesquisador. 2. ed. Ijuí: Unijuí, 2003.

MAZZEU, F. J. C. Uma proposta metodológica para a formação continuada de professores na perspectiva histórico-social. Caderno CEDES, v. 19, n. 44, p. 59-72, abr. 1998. 
MINAYO, M. C. S. O desafio do conhecimento: pesquisa qualitativa em saúde. São Paulo-Rio de Janeiro, HUCITEC-ABRASCO, 1992.

NORRIS, S. P.; PHILLIPS, L. M. How Literacy in Its Fundamental Sense is Central to Scientific Literacy. Science Education, v. 87, n. 2, 2003, p. 224-240.

NÓVOA, A. (org). Os professores e a sua formação. Portugal: Porto, 1992.

OLDONI, J. F. W. B.; LIMA, B. G. T. A compreensão dos professores sobre a Alfabetização Científica: perspectivas e realidade para o Ensino de Ciências. ACTIO, v. 2, n. 1, p. 41-59, jan./jul. 2017.

PETRUCCI, D.; URE, M. C. D. Imagen de la Ciencia en alumnos universitarios: una revisión y resultados. Enseñanza de las Ciencias, v. 2, n. 19, p. 217-229, 2001.

SANTOS, W. L. P. Educação Científica: uma revisão sobre suas funções para a construção do conceito de letramento científico como prática social. Revista Brasileira de Educação, v. 12, n. 36, set/dez., p. 474-492, 2007.

SANTOS, W. L. P.; MORTIMER, E. F. Uma Análise de Pressupostos Teóricos da Abordagem CT-S (Ciência - Tecnologia - Sociedade) no Contexto da Educação Brasileira. Revista Ensaio - Pesquisa em Educação em Ciências, v. 2, n. 2, p. 1-23, dez. 2002.

SASSERON, L. H.; CARVALHO, A. M. P. Almejando a alfabetização científica no ensino fundamental: a proposição e a procura de indicadores do processo. Investigações em Ensino de Ciências, v. 13, n. 3, p. 333-352, 2008.

SASSERON, L. H.; CARVALHO, A. M. P. Alfabetização científica: uma revisão bibliográfica. Investigações no Ensino de Ciências, v. 16, n. 1, p. 59-77, 2011.

SASSERON, L. H; MACHADO, V. F. Alfabetização científica na prática: Inovando a forma de ensinar Física. São Paulo: LF, 2017.

SOARES, Al. C.; MAUER, M. B.; KORTMANN, G. L. Ensino de ciências nos anos iniciais do ensino fundamental: possibilidades e desafios em Canoas-RS. Revista Educação, Ciência e Cultura, v. 18, n. 1, jan./jun, 2013.

VIECHENESKI, J. P., SILVEIRA, R. M. C. F. Alfabetização Científica por meio da abordagem CTS: um caminho viável à formação dos cidadãos. In: Simpósio Nacional de Ensino de Ciência e Tecnologia, 3, 2012, Anais... Ponta Grossa: UTFPR, p. 1-10. Disponível em: http://www.sinect.com.br/anais2012/html/artigos/ciencia/11.pdf. Acesso em: 19 jul. 2018.

VIECHENESKI, J. P.; CARLETTO, M. R. Iniciação à alfabetização científica nos anos iniciais: contribuições de uma sequência didática. Investigações em Ensino de Ciências, v. 18, n. 3, p. 525-543, 2013.

Recebido em outubro de 2020.

Aprovado em maio de 2021. 